\title{
Um instrumento avaliativo em larga escala baseado na concepçáo sociointeracionista da linguagem
}

\author{
Vânia Cristina Casseb Galvão*
}

\begin{abstract}
Resumo
Este artigo se fundamenta na análise de um instrumento avaliativo em larga escala, desenvolvido a partir da temática "mistério", baseada em uma leitura sociointeracionista dos itens do programa de conteúdos exigidos nas questóes de uma prova. Os dados foram analisados a partir de princípios funcionalistas, de base sociointeracionista, segundo os quais os gêneros são a instância da atualização linguística e a língua constituída em níveis mutuamente relacionados. Destacaram-se os conhecimentos relativos ao nível da configuração estrutural e funcional dos gêneros, ao nível informacional, ao semântico e ao gramatical. Além disso, há os aspectos positivos dessa configuração de prova como ferramenta avaliativa num concurso público.
\end{abstract}

Palavras-chave: avaliação em larga escala, conhecimentos linguísticos, sociointeracionismo, funcionalismo.

\section{A large-scale assessment tool based on the concept of the social interactionism of language}

\section{Abstract}

This article is based on an analysis of a large-scale assessment tool designed around the theme of "mystery", based on a social interactionist reading of content program items demanded by exam questions. Data were analyzed from the perspective of functionalist principles, on a socio- interactionist basis, according to which genres express levels of linguistic updating and language is constituted in mutually related levels. Knowledge of the level of structural and functional configuration of genres, of the informational level, of semantics and grammar are all highlighted. In addition, it presents the positive aspects of this configuration of the test as an assessment tool in a civil service examination.

Keywords: large-scale assessment, linguistic knowledge, socio-interactionism, functionalism.

* Docente do Departamento de Estudos Linguísticos e Literários, Faculdade de Letras-UFG e do Programa de Pós-graduaçấo em Letras e Linguística-UFG. Pesquisadora do CNPq. E-mail: vcasseb2@terra.com.br 


\section{Introduçáo}

As provas de língua portuguesa do Centro de Seleção da UFG, conforme a análise de vários programas do processo de vestibular e de concursos públicos, entre os quais, dos processos seletivos 2011-1, 2011-2, 20121, 2012-2; dos concursos públicos para a Prefeitura de Goiânia e para a Prefeitura de Aparecida de Goiânia, disponíveis em www.vestibular.ufg.br, são pautadas em uma concepção sociointeracionista da linguagem. Isso significa que o trabalho de análise linguística parte da materialidade linguística visível em gêneros discursivos, instâncias do processo interativo em suas múltiplas realizações. Logo, pressupóe-se que os fenômenos de linguagem, as regras da gramática e os sentidos decorrentes dos textos devem ser depreendidos pelos candidatos a partir da materialidade textual-discursiva. Esse tipo de expectativa implica a consideração, tanto para quem produz quanto para quem é avaliado por esse instrumento, dos aspectos contextuais culturais e situacionais do uso (HALLIDAY, 1985; NEVES, 2010).

A análise linguística com base nos usos da língua, materializados em gêneros, favorece diferentes abordagens avaliativas. Subjacente à macroestrutura de uma prova orgânica pode estar um determinado gênero discursivo como a carta, por exemplo; uma conjugaçáo de gêneros, como carta do leitor, carta argumentativa, carta de amor; uma dimensão discursiva, como o discurso jornalístico ou o discurso jurídico. Cabe também o trabalho a partir de textos em que predominem determinadas sequências discursivas ou tipos textuais, como o narrativo, o descritivo, o injuntivo, bem como cabe também o desenvolvimento de um instrumento avaliativo com base em um tema único ou em um tema combinado com outros dele derivados.

Neste artigo, analiso um instrumento avaliativo em larga escala, uma prova de orientaçáo sociointeracionista desenvolvida a partir de uma temática, "o mistério". Inicialmente, mostro o programa de conteúdos publicado para os candidatos de um concurso. Em seguida, apresento o instrumento avaliativo a ser analisado e, finalmente, a partir de uma leitura do programa de conteúdos segundo princípios teórico-metodológicos funcionalistas, representativos de uma abordagem da linguagem de orientação sociointeracionista, faço uma análise desse instrumento avaliativo. Nas consideraçōes finais, apresento as vantagens dessa abordagem, em uma ferramenta avaliativa de conhecimentos a respeito da língua portuguesa, num concurso público. 


\section{O programa de conteúdos}

$\mathrm{O}$ instrumento avaliativo ou prova-alvo deste estudo integra o concurso público relativo a vários cargos de nível superior da área de saúde, da prefeitura de Aparecida de Goiânia, cujas regras constam do edital 03/2012. O programa de conteúdos possíveis de serem explorados na prova tem a seguinte configuração:

\section{CONTEÚDOS PROGRAMÁTICOS}

1. Leitura, interpretação e análise de textos de diferentes gêneros textuais. Efeitos de sentidos produzidos nos textos.

2. Linguagem verbal e não verbal.

3. Mecanismos de produção de sentidos nos textos: metáfora, metonímia, paralelismo, ambiguidade, citação, pressuposto, subentendido, inferência, ironia, intertextualidade etc.

4. Uso de artigos, pronomes, substantivos e outros recursos estabelecedores da referência textual.

5. Utilização de mecanismos discursivos e linguísticos de coerência e coesão textuais (escolha lexical, progressão temática, paralelismo sintático e/ ou semântico, escolha e relevância dos tópicos e das informações em relação ao tema e ao ponto de vista assumido, orientação e força dos argumentos, repetiçãa, retomadas, anáforas, conectivos, pontuação), conforme o gênero e os propósitos do texto.

6. Funcionalidade e características dos gêneros textuais: ofício, memorando, e-mails, carta comercial, carta pessoal, aviso, charge, conto, crônica, tira, artigo de opinião e artigo de divulgação científica, reportagem, notícia, propaganda institucional/educativa, caricatura.

7. Funcionalidade e características dos diferentes discursos (jornalístico, político, acadêmico, publicitário, literário, científico etc.). Análise de indicadores presentes no texto para identificar as várias vozes do discurso e o ponto de vista que determina o tratamento dado ao conteúdo para confrontá-lo com o de outros textos, com outras opinióes e posicionar-se criticamente diante dele. 
8. Organização da frase. Sujeito e complemento sintáticos. Tempos e modos verbais. Modalidade. Voz verbal. Concordância verbal e nominal. Regência dos nomes e dos verbos. Adjetivos. Advérbios. Preposiçóes. Conjunções.

9. Formação das palavras. Composição, derivação. Acentuação gráfica.

10. Variação linguística: sociocultural, geográfica, histórica. Variação entre modalidades da língua (fala e escrita). Usos da língua no universo virtual.

11. Língua padrão normativa. Ortografia Oficial. Pontuação.

Para a análise aqui pretendida, esse programa de conteúdos receberá uma leitura a partir de uma perspectiva funcionalista da linguagem, que reconhece o ato discursivo como resultado de um evento de interaçáo, de uma atividade social. Essa leitura favorece o entendimento das bases epistemológicas desse processo avaliativo no que concerne ao conhecimento de língua portuguesa e, consequentemente, ajudará a vislumbrar o nível de competência linguística esperado para um profissional de saúde, de nível superior, no exercício de atividades interativas gerais.

\section{O instrumento avaliativo}

A prova de língua portuguesa do concurso para preenchimento de vários cargos na área da saúde, da Prefeitura de Aparecida de Goiânia, é constituída por 15 questóes de múltipla escolha e, conforme se depreende dos textos selecionados e das questôes mais voltadas para a organização do conteúdo, foi desenvolvida a partir da temática "mistério". Para isso, elegeram-se dois textos verbais: uma entrevista, em cujo título se destaca o caráter enigmático, misterioso de John Malkovich, um importante ator e diretor de cinema e televisão; e um trecho do livro Os miseráveis, de Victor Hugo, em que os eventos que se sucedem dáo o tom misterioso à cena enunciativa. $\mathrm{O}$ último texto da prova é de natureza não verbal: uma fotografia artística, que remete a um buraco de fechadura, objeto muito solicitado para construir sentidos no universo discursivo do mistério.

A seleção textual demonstra um trabalho consciente, de modo a oferecer ao candidato material cognitivo e discursivo para embasar suas reflexóes acerca da linguagem, tanto no que diz respeito às inúmeras possibilidades de construção de sentido e de reflexão sobre a estrutura quanto ao que se relaciona ao funcionamento da linguagem posta em ação. 


\section{A seguir, reproduzo o instrumento avaliativo em análise:}

\section{LINGUA PORTUGUESA}

Leia o texto 1 para responder às questöes de 01 a 08. Texto 1

\section{O misterioso Sr. Malkovich}

Por trás do rosto famoso do astro do cinema intemacional e ator aficionado de teatro, quem é o verdadeiro John Malkovich?

Seu poder de atração é perturbador e enigmático, reforçado por um olhar magnético. Ele fala baixinho, como se cochi-
chasse... John Malkovich é um homem que cabe em muitas fantasias. Entre cinema de arte e as produçoes comerciais (Ele ficou famoso com Império do Sol, A troca), o mais europeu dos atores americanos (ele tem ancestrais croatas, escoceses, franceses) sempre representou personagens à beira do grotesco. Esta conversa aconteceu em Paris, no periodo em que atuava como diretor da versäo para o palco de $L$ gaçỏes perigosas, drama que foi seu passaporte para o estrelato internacional quando, em 1988, trabalhou no filme do mesmo nome, dirigido por Stephen Frears.

P: Como você se descreveria como diretor?

$\mathrm{R}$ : Eu me comparo a um treinador de futebol que se restringe a delinear a jogada da equipe. Os atores é que têm de representar, não eu. Portanto, não me preocupo em thes dizer como criar seus papéis. Deixo-os livres para seguirem os próprios instintos. $\mathrm{E}$ eles o fazem com muita inteligência.

$\mathrm{P}$ : Você já disse muitas vezes que é autodidata. Acha que esse é um ponto forte?

R: Acho que nasci assim! Ir à escola e aprender tiçōes sempre esteve além da minha capacidade. Como se aquilo fosse uma linguagem completamente diferente. Desde os 5 ou 6 anos eu soube que teria de entender tudo sozinho.

P: Por quê?

R: Meu pai decidiu criar os cinco filhos assim. Sabíamos a hora de ir para a cama, de levantar, de comer... sem ninguém mandar. Talvez uma liberdade tăo imensa seja pressão demais para uma criança, mas tudo bem, sobrevivil Além do mais, o destino dos seres humanos é nắo ter ninguém que possa resolver seus problemas. Sei que a maioria discorda e acha que cabe ao Estado cuidar de tudo. Eu, năo.

$P$ : A raiz europeia foi um fator importante na sua formação?

R: Meus avós nāo sabiam falar inglès, mas não queriam que aprendêssemos servo-croata. Naquela época, todos queriam se tornar americanos a qualquer preço. Mas sempre fui fascinado pela cultura europeia. Por isso, passei 25 anos, quase metade da minha vida, na Europa.

P: Que valores seus pais the passaram e você acha úteis até hoje?

R: Que cabe a mim - e só a mim - avaliar o que faco na vida. Que sempre devemos nos esforcar para melhorar. É melhor ser assim, porque, de qualquer forma, todos vamos morrer um dial (Ele dá uma risadinha).

P: Essa possibilidade o assusta?

R: Não, sei que um dia me reunirei com meus imăos que recentemente deixaram este mundo. Mas levo uma vida belissima e espantosa, conheci pessoas incriveis. Chegará a época de deixar que outros tenham oportunidade.

P: Desde que apareceu como Deus ao lado de George Clooney naquele comercial de uma marca de café famose você quase alcançou maior prestígio pelo comercial do que pelos papéis em filmes. O que acha disso?

R: Nada. Nunca me achei interessante como assunto. $E$ isso antes mesmo de me tomar uma pessoa dita famosa.

$P$ : Entre os cerca de 70 filmes que fez, qual significa mais para você?

R: Ligaçōes perigosas, O céu que nos protege... mas meus primeiros papéis como ator também me causaram grande impressảo. Porque foi com eles que entendi que minha vida seria diferente. Seja como for, parte de mim sempre preferiu o exílio.

$P$ : O que o motiva agora?

R: A curiosidade. Alcancar outras pessoas, diversificar os interesses... Se sinto vontade de fazer alguma coisa, eu faço. (Ele chegou a lançar uma coleção de roupas). Por isso não tenho nenhum desejo secreto ou não realizado!

SEIEÇŌES. Săo Paulo: Readers Digest, ago. 2012. p. 61-62. (Adaptado).

\section{— QUESTÃO 01}

Todo texto tem informaçőes novas, informaçőes velhas ou inferiveis do próprio discurso. Que pergunta do entrevistador aciona conhecimentos prévios sobre John Malkovich?

(A) Como você se descreveria como diretor?

(B) Essa possibilidade 0 assusta?

(C) O que o motiva agora?

(D) Por quê?

\section{- QUESTÄO 02}

As duas primeiras respostas de John Malkovich apresentam um padrão argumentativo que se repete ao longo de sua fala. Esse padrāo é composto de argumentos em que ele

(A) compara suas atitudes com as de outros artistas, revelando uma personalidade instável e excêntrica.

(B) mostra uma preocupação, confirmando sua fama repentina.

(C) aciona fatos de sua vida cotidiana, exemplificando atitudes aventureiras.

(D) minimiza suas qualidades, deixando transparecer atributos como liderança e genialidade. 
166 Polyphonía, v. 23/1, jan./jul. 2012

$\underline{\text { UFG/CS }}$ CONCURSO PÚBLICO

APARECIDA DE GOIÂNIA - SAÚDE/2012

\section{- QUESTÃO 03}

A aparente incompletude da pergunta "Por quê?" é produtiva para a configuração da entrevista. Sua presença garante

(A) discurso eloquente, sem mostrar a razão para a independência do ator.

(B) grau de formalidade alto, para satisfazer a forma de tratamento exigida pelo entrevistado.

(C) fluidez de uma conversa espontânea, sem afetar o planejamento do entrevistador.

(D) resposta curta, para resumir o conteúdo apresentado na fala de John Malkovich.

\section{- QUESTẢO 04}

Que efeito de sentido é produzido com o uso de "e só a mim" na fala de John Malkovich a respeito de suas heranças familiares?
(A) Convicçăo.
(B) Dependência.
(C) Covardia
(D) Descompromisso.

\section{- QUESTÃO 05}

O trecho que nega a caracteristica atribuida a John Malkovich no título da entrevista e o traço de sua personalidade que ele mais deixa transparecer ao longo de sua fala sáo:

(A) "Seja como for, parte de mim sempre preferiu o exílio" - timidez.

(B) "todos vamos morrer um dia!" - medo.

(C) "Nunca me achei interessante como assunto" - humildade.

(D) "Acho que nasci assim!" - contormismo.

\section{- QUESTÃO 06}

$\mathrm{Na}$ avaliaçăo de sua carreira, John Malkovich destaca

(A) o inusitado.

(B) o poder.

(C) a fama

(D) a longevidade.

\section{- QUESTÃO 07}

No trecho "Portanto, năo me preocupo em lhes dizer como criar seus papéis. Deixo-os livres para seguirem os próprios instintos", a diferença na escolha dos pronomes "lhes" e "os" é determinada

(A) por quem fala.

(B) pelo tipo de complemento exigido pelo verbo.

(C) pela presença de nomes de conotaçăo abstrata.

(D) pela pessoa a quem os pronomes se referem.

\section{- QUESTÃO 08}

No texto, os parênteses acrescentam informaçōes a respeito do entrevistado. A informação que confirma a impulsividade de John Malkovich é:

(A) "(Ele dá uma risadinha)".

(B) "(Ele chegou a lançar uma coleção de roupas)".

(C) "(Ele ficou famoso com Império do Sol, A troca)".

(D) "(Ele tem ancestrais croatas, escoceses, franceses)".

\section{- RASCUNHO}


Polyphonía, v. 23/1, jan./jul. 2012167

Leia o trecho de romance (texto 2) a seguir para responder às questōes de 09 a 12.

Texto 2

\footnotetext{
Naquela noite, ao sair do quarto para comer, o bispo ouviu a criada conversando com a irmā dele. $\mathrm{O}$ assunto era bastante familiar ao dono da casa. A criada năo se conformava com o fato de a porta não ter trinco nem fechadura Quando fora fazer compras, soubera que um homem malencarado tinha chegado à cidade.

- Verdade? Surpreendeu-se o bispo.

- Todos estảo com medo de que alguma desgraça aconteça esta noite. Năo existem lanternas nas ruas para dar um pouco de luz! A policia não funciona! Digo e repito, $\mathrm{e}$ sua irmã concorda comigo, que...

- Eu nāo disse nada - interrompeu a irmã do bispo $\mathrm{O}$ que meu irmão faz está bem feito.

A criada prosseguiu, como se não tivesse ouvido nenhum protesto:

- Nós diziamos que esta casa näo oferece nenhuma segurança. Se o senhor bispo me permitir, vou chamar o serralheiro para colocar de volta as fechaduras e os ferrolhos. Esta porta, que qualquer um pode abrir, é um perigo! Além disso, o Monsenhor manda entrar qualquer um que bate à porta, mesmo no meio da noite..

Nesse instante, alguém bateu com força.

- Entre-disse o bispo.

A porta se abriu. Entrou um homem. Era o forasteiro que já conhecemos vagando pelas ruas à procura de abrigo. Deu um passo para frente e parou. $O$ saco de viagem nas costas, o cajado na mão. Seu olhar era rude, violento, mas também cansado. lluminado pelo fogo da lareira, parecia assustador. A criada tremeu. A irmã ficou aterrorizada por um instante.

HUGO, Victor. Os miseráveis. Tradução de Walcyr Carrasco. São Paulo: FTD, 2002. p. 19
}

\section{- QUESTÃO 09}

Qual a funçăo do primeiro parágrafo desse trecho do romance para o desenvolvimento da trama?

(A) Apresentar o ápice das ações.

(B) Estabelecer uma sequência argumentativa e o discurso direto.

(C) Desviar a atenção do leitor da temática central.

(D) Introduzir os personagens e o fato gerador do conflito.

\section{- QUESTÃO 10}

Que recurso linguístico é especialmente relevante para criar o clima de suspense no texto?

(A) O enunciado com dupla negação na fala da irmã do bispo.

(B) O travessão para distinguir a voz das personagens.

(C) A escolha lexical para designar pessoas e acontecimentos.

(D) A alternância entre verbos no presente e no passado.

\section{— QUESTÃO 11}

Uma das estratégias do jogo de linguagem que estabelece o suspense está relacionada à alteração na percepção da realidade. Um exemplo dessa alteração é:

(A) uma criada ter suas palavras criticadas pela irmã do bispo.

(B) um religioso importante ter sua própria irmã como hóspede.

(C) uma pessoa comum vir a questionar as decisões de uma autoridade eclesiástica.

(D) um fato corriqueiro como bater à porta se transformar num evento relevante.

\section{—QUESTÃO 12}

Além de expressar condicionalidade, a oração "Se o senhor bispo me permitir", na fala da criada dirigida ao bispo, demonstra

(A) subserviência.

(B) arrependimento.

(C) incredulidade.

(D) agressividade.

\section{- RASCUNHO}


168 Polyphonía, v. 23/1, jan./jul. 2012

UFG/CS

CONCURSO PÚBU ICO

APARECIDA DE GOIANIA - SAÚDE/2012

Leia o texto 3 a seguir para responder à questāo 13 .

Texto 3

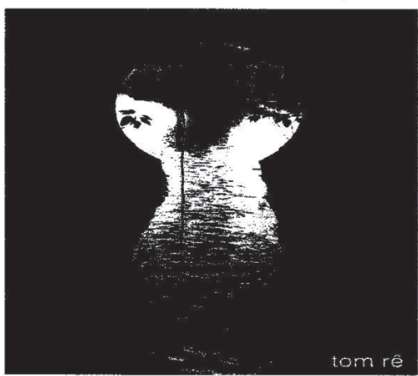

RE, Tom. Buraco da fechadura. Disponivel em $<$ olhares/uol.com.br. Acesso em: 6 set. 2012.

\section{- QUESTĀO 13}

A referência a um buraco de fechadura construida a partir da cena do cotidiano fotografada por Tom Rê ocorre por

(A) multiplicação

(B) associaçăo.

(C) subtraçăo.

(D) divisão.

Releia os textos 2 e 3 para responder à questão 14

\section{- QUESTÃo 14}

O buraco de fechadura é um símbolo muito presente nas histórias de mistério. Considerando-se a configuraçăo formal do texto 3 e os jogos de linguagem que levam à produção do suspense no texto 2 , esse símbolo representa

(A) uma passagem entre a segurança e o sinistro.

(B) a ligaçäo das personagens principais e secundárias.

(C) a empatia entre o autor e o leitor.

(D) uma medida temporal e espacial definida. 
Apresentada a prova, segue a análise desse gênero como instrumento de avaliação que privilegia a competência comunicativa em detrimento do conhecimento enciclopédico da língua, calcado em reconhecimento de regras de padronizaçáo escrita e em reconhecimento de nomenclatura (ANTUNES, 2007). A constituição formal e funcional da prova mostra que se trata de um instrumento avaliativo cujo projeto de construçâo é metadiscursivo, ou seja, é um exemplar eficiente de um texto avaliativo, que cumpre os propósitos a que se destina: o enunciado das questóes propóe, de fato, um problema a ser resolvido; não são percebidas alternativas mutuamente exclusivas, negativas, ou que configurem armadilhas para os candidatos; há harmonia na extensão das alternativas; os conteúdos foram explorados de modo a acionar sentidos explícitos e implícitos, decorrentes dos usos linguísticos, entre outras características que dão ao texto leveza, fluidez e força avaliativa.

\section{Análise do instrumento avaliativo}

Entre os pressupostos teóricos funcionalistas que sustentam a análise da prova estão: a) na organização da gramática das línguas, o nível sintático se realiza por meio da semântica e é acionado por motivaçóes pragmáticas; b) a pragmática é a dimensão que atualiza o contrato sociointeracional dos usuários da língua; c) a língua se atualiza por meio de gêneros discursivos, ou seja, o gênero é a esfera da atividade interativa (cf. CASSEB-GALVÂO, 2011a, 2011b).

Esses princípios favorecem o entendimento de que os arranjos linguísticos estấo a serviço da produção de sentidos, consideradas as regras do contrato sociointerativo, estabelecidas em função do contexto situacional (interativo) e do cultural (coletivo). Logo, não há fenômeno gramatical que ocorra desconectado das intenções e das interpretaçóes pragmáticas dos usuários da língua.

Reconheço a gramática como uma "engrenagem" que movimenta o contrato sociointerativo segundo regras estabelecidas discursivamente e, por isso, sua organização envolve dimensóes relativas ao componente discursivo e ao componente estrutural da linguagem. Assim, os níveis de constituição linguística - sintático, semântico, pragmático, informacional, textual, discursivo etc. - se inter-relacionam para produzir sentidos nos textos. 
Essa inter-relaçáo, no entanto, não impede a distinção dos fenômenos relativos a cada um desses níveis, mas dificilmente um problema a ser resolvido em determinada questáo da prova, por exemplo, mobilizará uma única habilidade. Por isso, por uma questáo de sistematização da análise, levarei em consideraçáo os aspectos funcionalistas mais encarecidos no problema proposto no enunciado das questóes.

As perguntas que orientam a análise são as seguintes: que conhecimentos previstos no programa foram exigidos na prova? Que princípios funcionalistas subjazem à solicitação desses conhecimentos?

A análise da prova mostra que os conteúdos foram explorados de maneira harmônica. Apesar de alguns terem sido abordados mais de uma vez, não há o predomínio de um deles. As questôes foram elaboradas de modo a exigir do candidato conhecimento a respeito dos mecanismos de produção de sentidos no texto (pressuposto, inferência, interdiscursividade), da organizaçáo argumentativa (padrão argumentativo, desenvolvimento temático), das características dos gêneros (entrevista, romance de mistério), dos efeitos de sentido produzidos por escolhas lexicais específicas, da análise de indicadores linguísticos para identificar vozes e confrontar opinióes, do uso da norma padrão da língua (regência, pontuação, uso dos pronomes).

Diante desse quadro, e, em razão das condiçóes de produçóes deste artigo, a análise dos princípios funcionalistas acionados na prova destaca, nos respectivos parágrafos, os conhecimentos relativos à configuraçáo dos gêneros e do universo discursivo em destaque na prova, e aqueles relativos ao nível informacional, ao nível semântico e ao nível gramatical.

$O$ funcionalismo reconhece que os gêneros atualizam a linguagem verbal e a não verbal, e, dependendo de motivações sociais, e das intençóes pragmáticas dos interlocutores, ambas se complementam na busca dos sentidos pretendidos. Os gêneros realizam-se em diferentes instâncias da vida social privada e pública, e acionam representaçóes de inúmeros universos discursivos ou campos de significaçôes particulares. Esse postulado é referendado na prova pela seleção textual e, especialmente, pela questão 14, que explora a simbologia do "buraco da fechadura" no universo discursivo do mistério e o seu papel na construção do jogo de suspense. Também a questão 3 , ao abordar o uso de uma forma aberta (interrogativa) para dar fluidez e espontaneidade à entrevista, enfoca uma característica relevante desse gênero. Merece destaque o enfoque aos elementos do universo discursivo do suspense (constitutivos de gênero), tanto no nível das sequências textuais 
narrativas (Questáo 9) quanto no nível lexical, ao se promover uma análise das escolhas lexicais como responsáveis pelo estabelecimento do clima de mistério nos textos dessa natureza (Questão 10) e as consequências dessas escolhas no nível semântico, ao mostrar que elas subvertem a percepção da realidade e fazem acontecimentos corriqueiros ganharem relevância contextual (Questão 11).

A primeira questão da prova aciona conhecimentos a respeito do nível informacional do gênero entrevista, e dos textos em geral, ao remeter ao status das informaçóes atualizadas discursivamente que, para Dik (1989), podem ser novas, dadas ou inferíveis do discurso. O modo como o problema foi proposto leva o candidato a fazer inferências para identificar um conhecimento adquirido previamente pelo entrevistador e que foi mobilizado no fluxo interativo, o que é uma informação fundamental para justificar a própria entrevista, e que, por isso mesmo, abre a série de perguntas da entrevista, pois diz respeito à atuaçáo do entrevistado como um renomado diretor de cinema. A Questão 8 também explora o nível informacional da entrevista ao enfatizar a função dos parênteses: acrescentar informaçóes à fala do entrevistado, entre as quais, a exemplificação de uma atitude que mostra o seu caráter impulsivo.

Depreende-se do conteúdo abordado que é esperado do candidato o reconhecimento de que o significado das expressões linguísticas é atualizado discursivamente e produz efeitos de sentido. Logo, os sentidos são contextualmente construídos, no contexto situacional ou cultural (NEVES, 2010), e as expressões linguísticas são mediadoras de sentido (DIK, 1989). Sáo princípios demonstrados mais explicitamente nos problemas propostos nas Questóes 4 e 15, que exploram, respectivamente, uma das possibilidades de sentido produzidas pelo uso de "e só a mim", no caso, indicando convicção, e a polissemia da palavra "mistério", indicando algo surpreendente, inusitado. Há vários recursos de linguagem que cooperam para a construção, a deturpação, a transformação e a transgressão dos significados básicos (CANÇADO, 2005), como a polissemia, recurso também explorado na Questão 12.

Como os subsistemas gramaticais colaboram para o estabelecimento da referência textual, segundo Lyons (1977, p. 174), a referência diz respeito à relação entre uma expressão linguística e o seu significado em ocasióes discursivas particulares; logo, a referência é construída pelos interlocutores. Artigos, pronomes, substantivos integram alguns desses subsistemas. Nos 
textos não verbais, a referência pode ser direta, como nas fotografias tradicionais, ou indireta, como nas fotografias artísticas, que exigem do leitor inferências que vão dar significado às imagens sugeridas pela fotografia. Os mesmos exercícios cognitivos que estabelecem a referência verbal estabelecem a não verbal. $\mathrm{Na}$ Questão 13 , por exemplo, espera-se que o candidato reconheça a associação como o processo semântico que faz o leitor compreender as formas produzidas pela fotografia de um riacho passando através de uma manilha como um buraco de fechadura. Essa mesma associação é exigida do candidato para analisar o padrão argumentativo que se repete nas duas primeiras respostas de John Malkovich, palavras que remetem a atributos como liderança e genialidade (Questão 2).

\section{Consideraçóes finais}

A concepção de linguagem que rege o instrumento avaliativo analisado favorece inúmeras possibilidades de desenvolvimento estrutural e conteudístico. A relevância da abordagem "temática" está no fato de que há um aproveitamento exponencial do frame cognitivo possível de ser acionado na escolha do tema da prova, ou seja, favorece que o candidato faça inúmeras relaçôes a partir das irradiaçóes semântico-discursivas que um tema como "mistério" pode proporcionar.

Sem abrir mão do trabalho com o uso da língua nem das regras da norma padrão escrita, a noção de gênero é trabalhada sem engessamentos. A prova explora ao máximo as possibilidades de análise nos vários níveis de organização linguística, bem como os conteúdos discursivamente em relevo nos textos.

O candidato tem a oportunidade de exercer seu conhecimento linguístico, mostrando competência comunicativa, atuando como linguista, característica natural de todo usuário da língua. Ele não apenas marca um cartáo-resposta indicando a resposta certa, ele faz um caminho de inferências, uma trajetória de raciocínios que valoriza sua criatividade, aguça e recupera conhecimentos internalizados, oferecendo a oportunidade de resolver problemas e apontar soluçóes e, o melhor de tudo, aprender enquanto é avaliado para a vida.

\section{Referências}

ANTUNES, I. Muito além da gramática. São Paulo: Parábola, 2007. 
CANÇADO, M. Manual de semântica. Belo Horizonte: Ed. UFMG, 2005. CASSEB-GALVÃO, V. C. Um exemplo de avaliação em Língua Portuguesa a partir da noção de gêneros. Interacçôes, Portugal, v. 19, p. 156-173, 2011 a. CASSEB-GALVÃO, V. C. A gramática a serviço dos gêneros. In: I Simpósio Internacional de Ensino de língua portuguesa, 2011, Uberlândia. Anais do I Simpósio Internacional de Ensino de Lingua Portuguesa - I SIELP. Uberlândia: UFU, v. 1, p. 1-10, 2011 b.

DIK, S. C. The theory of Functional Grammar. Dordrecht: Foris Publications, 1989.

HALLIDAY, M. An introduction to Functional grammar. Londo: Edward Arnold, 1985.

LYONS, J. Semantics. Cambridge: Cambridge University Press, 1977. v. 2.

NEVES, M. H. M. Texto e gramática. São Paulo: Contexto, 2006.

NEVES, M. H. M. Ensino de lingua e vivência de linguagem. São Paulo: Contexto, 2010.

Recebido em: 3 nov. 2012

Aceito em: 5 dez. 2012 